\title{
A Research on the Effects Task-based Language Teaching Have on Vocational College Students' Interest in Learning English
}

\author{
Bojun Zou \\ Graduate School \\ Jilin Agricultural University \\ Changchun, China
}

\author{
Jianzhong Zhou* \\ The Faculty of Arts and Humanities \\ Jilin Agricultural University \\ Changchun, China
}

\begin{abstract}
Task-based Language Teaching (TBLT. abbreviation) is defined as a creative teaching method which advocates students to bring second language into full utility and takes improvement of students' pragmatic competence as a goal. It is acknowledged that a great number of vocational students take less interest in leaning English and play truant at times. Based on summary of researches and related theoretical foundations, it is supposed to consider the application of TBLT in higher vocational English class as a starting point, adopt quantitative and qualitative methods, aimed to explore how to stimulate students' interest in learning English through TBLT and further enhance comprehensive English proficiency. It is believed that achievements in TBLT implemented in higher vocational English teaching will be enriched and the English teaching reform is bound to be deepend along with entire vocational education accelerated.
\end{abstract}

Keywords-TBLT; learning interest; vocational education; teaching reform

\section{INTRODUCTION}

Higher vocational education is employment-oriented and develops high-quality skilled personnel armed with production, construction and management services as the educational target, of which essential characteristic determines to focus on cultivating practical ability.

China State Department clearly stated in the "Decision on Accelerating the Development of Vocational Education" issued in 2013 , to promote the innovation of training mode, spread cooperative learning and implement project teaching as well as process-oriented model. In order to satisfy the urgent demands of the world economic recovery, it requires that the majority of vocational colleges organically combine basic knowledge with communicative competence in training links.

However, currently, compared with the objectives above, teaching effects in a great quantity of vocational colleges are reverse. Various Sources and uneven enrollment results, students are labeled with "good-for-nothing" "poor level". Therefore, both improvement of academic performance and harmonious personality are seriously restricted by the phenomenon of ignorance of English itself, lack of interest and

*Corresponding Author: Jianzhong Zhou shortage of motivation.

Ushinski once said, if study comes along with disincline or compel, it stifles the desire of acquiring knowledge. In fact, interest is regarded as one of the most considerable psychological factors of motivation and the most realistic and active internal intention. Hence, not only is the fact-that how to stimulate students' interest in learning English and heighten English practical ability-is the objective to be achieved, but also an effective access to English teaching reform.

At present, researches on TBLT mostly concentrate in the theoretical summary stage and less empirical cases were accumulated. It is a pity that papers on this top seem still blank in Northeast China. How to crack the dilemma in practice? How to design tasks to fire students' learning interest? It is the actuality above that is waited to be solved which is the initial inspiration to launch the plan.

I sincerely urge colleagues to put forward any opinions and suggestions when necessary and share your own valuable experience. Let us give TBLT a hand to be propagated over China represented for developing countries (English Second Language).

\section{LITERATURE REVIEW}

"Do things in language" is always advocated by TBLT. It deeds application as the purpose and core and provides students with an unprecedented practice space by participation, experience, interaction, exchange and cooperation to mobilize existing language resources.

\section{A. Abroad Summary of TBLT}

TBLT theory originated in Western Europe, firstly fulfilled in the mid 20th century in India on behalf of countries (English Second Language), shaped in seventies, in the late 1980s matured and widely used in Europe and North America. Overall, fruitful theoretical achievements have been made, enriched, consolidated and deepened in practice.

Clearly defined tasks is the first prerequisite. Synthesizing the definitions resulted by Long, Prabhu, Nunan, Ellis and other scholars, it is believed that the task has the following characteristics: the practice with a distinct purpose; continuous 
interpersonal activity; conscious thinking activity by wielding the target language. According to actual requirements and professional development, the task, in this study, is defined to be an activity by which students apply English to analyze and solve problems in simulation.

Designing a task is the core. Numan concluded the authenticity principle and the task dependency. As for the degree of difficulty, Skenhan proposed "3C Mode" complexity, cognitive complexity and communicative complexity. Summing the views above up, when design a task, it is supposed to consult professional needs, consider students' interest and remember to regard students themselves as the center.

Implementation is the keynote. Willis put forward three steps namely Pre-Task, Task-cycle and Language Focus.

It is absolute that TBLT and traditional "3P Mode" (Presentation, Practice, Production) ought to be adopted in accordance with the actuality rather than mutually replaced. It goes without saying that mutual supplement is certain to promote reform.

Thus, obviously, no matter in terms of definition, design and implementation, the studies abroad have formed a mature system. They are expounded detail and have been applied to the second language teaching practice. In recent years, research on TBLT has begun to get involved in social and cultural fields which will open up a boundless vitality of the territory.

\section{B. Domestic Current Status of TBLT}

At the end of 1990s, the concept of TBLT was introduced by Xia Jimei etc., which began to spread across China. In the Early of 21th century, "English Curriculum Standards", was addressed by Ministry of Education and then some Task-Based Teaching method and comprehensive practical ability was referred, which set off a heated wave. Yue Shouguo described how to design tasks. Fang Weili proposed "Focus-type Taskbased Teaching". The initial spread of cognitive errors and progressive achievements were separately summarized by Yang Guiqin and Tian Ling.

Subsequently, TBLT gradually was employed to English teaching. By means of a flexible set tasks, the English grades of some high school experimental students were significantly enhanced by Liu Junyi. Zhu Yuelan brought TBLT into college comprehensive English course, and noted the necessity to cultivate pragmatic competence. Wang Xiao's experiment was shown that the interest, in learning English of which the sample in a certain higher vocational school, was effectively stimulated and the grades were substantially increased. Liu Shufeng thoroughly analysed its necessity and took some unit as a teaching example to illustrate the possibility.

\section{Comments on Literature Review}

Researches in domestic mostly focused on TBLT application in colleges and high schools, in favor of literature translation and theory induction, on the contrary, empirical cases in close connection with current situations of English teaching in vocational colleges are handful. Moreover, papers published in the same period revolved around the similar issue, demonstrated a high repetition rate.

Throughout the perspectives above, it could be easily found that they were either a single study of TBLT from a respect utilized into English class application or an exploration of the factors that affect the interest from psychology. It is pity that two perspectives originally united were separated and theoretical results deepened from practice were useless.

\section{THEORETICAL BASIS \& ACTUAL CONDITIONS}

\section{A. Theoretical Basis}

1) Second Language Acquisition Theory: Krashen believes that the structure of language acquisition obeys along with a predictable order. Men naturally acquire language in communication by means of importing reading and listening materials which are a bit more complicated than current level and meanwhile noting the denotation of language itself. Emotional factors such as motivation, interests and personality which play an active role, are attached importance to by Krashen. TBLT stresses the function of understanding. In the stage of task-design, full consideration including legibility, savour and sequence is given. Both interest in learning and comprehensive ability are premeditated at first place. Above all, TBLT brings the second language acquisition theory into creative play.

2) Constructive Learning Theory: Synthesizing the philosophies including Piaget's cognitive development comprehensive, Ausubel's meaningful learning theory, Bruner's discovery learning and social constructive learning theory, the cognitive structures discovered and perceived by learners are contents which are meaningful to them. Furthermore, subjective factors regarding background knowledge and attitudes, which is part of learners themselves, cannot bypassed at any time. The primary effect of implication is emphasized by TBLT, wherefore, it requires that the purpose of communicative tasks ought to be defined in order to ensure activities themselves to make a difference.

3) Multiple Intelligence Theory: In the framework of Canard's Multiple Intelligence, everyone's intelligence has different manifestations. That is to say, as long as there are adequate external influences and their own efforts, each individual will be able to develop and strengthen their own any kind of intelligence. On the task-based classroom, teachers fully master students' intelligence features when designing tasks, and afterwards these which satisfy the zone of the proximal of the majority are devised. Students mobilize their comparative strengths as soon as prepare and cooperate to complete the task. Teachers are expected to tap subtle potential of students as multi-angle as possible, extend seasonable recognition and have students gain a sense of harvest.

4) Humanism Learning Theory: The theory is represented by Rogers' Learner-centered "theory, which claims that students are supposed to actively study on their own. "Teach" 
is not the ultimate but the aim is defined that teachers had better provide students with resources as many as possible and guide students to explore methods so that novices possess the ability to grasp creative learning. TBLT always insists on student-centered, which means students are on top of professional knowledge and develop their own capabilities after process of finishing tasks. In a word, both of them originate from the same value orientation.

\section{B. Actual Conditions}

1) Advantages of Realistic Basis: Two parallel classes specializing in Sales and Marketing at a higher vocational school in Changchun will be selected. Its feasibility exists in the fact the majority of the students chosen are enthusiastic, active, good at action and longing for more new knowledge related to their future job. Students newly enrolled suddenly get rid of the extremely tremendous pressure on the college entrance examination, tired with the traditional teaching model namely listen-to-write and test-to-test. On the contrary, fascinating, friendly and visual-image teaching style caters to them, which arouses desire for knowledge and makes a sense of achievement. According to observation, vocational students' ability in social intercourse and following fashions is more extinguished than college scholars. Because it is a piece of cake to find living themes in close connection with the task topics, in case that teachers timely guide and active classroom activities. Thus, it is uncomplicated to motivate enthusiasm, which contributes to carry out this teaching experiment.

2) Advantages of scientific research atmosphere: It is compliant with the professional requirements of the study that the author is engaged in vocational and technical education whose direction is education management. Through one academic year, professional courses have been mastered and the skill of theory into practice has been formed.

Jilin Agricultural University, where the author is studying, is equipped with excellent conditions from material assets, professional teachers to academic atmosphere. She was one of the most earliest established Master Degree Programs of Vocational and Technical Education; "National Key Construction of Vocational Teachers' Training Base" titled by the Ministry of Education.

Tutor Professor Zhou Jianzhong, director of China Vocational Education Professional Development Committee, has published more than thirty professional papers in heated educational core journals. Professor Zhou has constantly been invited to participate in the international conferences on education. Professor Zhou has devoted countless effort to prearranging, selecting theme, thesis proposal and modification. He often sacrifices his rest time to discuss the optimal program with the author and selflessly shares his valuable personal experience.

\section{RESEARCH SIGNIFICANCE}

\section{A. The Theoretical Results is to Be Enriched}

Specifically, it is paid attention to vocational college students who are always neglected by society and put TBLT application in vocational required English as an intervention. It is considered timely to fill up the gaps of the existing research and broaden the perspective of teaching reform in vocational theoretical research.

\section{B. The Teaching Reform will Be Accelerated}

It is encouraged that previous similar studies vague style is abandoned. Combined with related empirical cases, it strives to provide targeted recommendations on how to enhance English proficiency of vocational college students. It is a fruitful practice to cultivate high-quality technical talents, which demonstrates to be a potential value and it hopes to offer an available reference for further similar studies.

\section{RESEARCH OBJECTS AND METHODS}

\section{A. Research Objects}

- Through implementation, the sample's interest in learning English will be excited, held and extended for more long time.

- Sample's English comprehensive competence will be effectively enhanced.

- It might as well try to promote the application of TBLT in higher vocational English class in Northeast China.

\section{B. Research Contents}

Five parts will be included as follows:

- definition of related concepts and literature reviews

- the theoretical basis of TBLT and prevailing conditions

- the scheme of TBLT experiment

- analysis of results

- recommendations and prospects

\section{Research Methods}

1) Literature Review: Use various channels to collect and organize documents and materials so as to obtain a theoretical knowledge about the method of this study as the main purpose. Depending on these data identification, classification, master academic achievements at home and abroad in this research.

2) Classroom Observation: In order to observe and record actual situations, it is going to step into the front line of English classroom. Numerous real, typical, general psychology and behavior of interviewees is investigated in purpose.

3) comparative Experiment: Two parallel classes selected is going to be respectively made full use of traditional 
teaching method and TBLT. After a semester, compare whether context interest is different and furthermore analyze impacts brought by TBLT on students interested in learning English.

\section{DifFICULTY \& SOLUTION}

\section{A. Inadequate theoretical support}

Although a considerable number of first-hand empirical results have been specifically consulted by the author, there is still some space waited to be filled in. Additionally, the author is a substitute English teacher who has not formed own unique style. Consequently, dilemma caused by inadequate theoretical support may appear in the experiment stage. To surmount this difficulty, the author intends to expand reserves of theory, as possible to bring theoretical results into survey and generalize results in timely. With the guidance of professional teachers as well as inspiration of experts, the deficiency will be force-fed.

\section{B. Negative attitude from sample}

TBLT as a up-to-date in China education sector, is still in spread stage. A part of professional teachers hold exclusive attitude, who firmly follow the traditional concept. It is the disadvantage to carry out this experiment. Moreover, sample students are weary of learning English, whose attendance cannot be guaranteed, let alone accept a new method of learning. Aimed to successfully implement this proposal, the author determines to frequently visit the sample school in order to obtain trust from teachers. Making full use of the pretest opportunity, more efforts will be made to melt their resentment, which may lay a solid foundation for qualitative interviews and observation.

\section{Qualitative research on test}

It cannot be led three-dimensional, comprehensive and dynamic evaluation to students' proficiency, if exclusively juxtapose pretest and post-test. Classroom observation will be involved to record subjects in the classroom activities including comparative study under non-standardized testing program. If possible, oral tests are recommended to be adopted by teachers which may contribute to unearth students' potential as well.

\section{ACKNOWLEDGMENT}

I would like to express my gratitude to all those who helped me during the writing of this thesis.

My deepest gratitude goes first and foremost to Professor Zhou Jianzhong, my supervisor, for his constant encouragement and guidance. He has walked me through all the stages of the writing. His unwavering support has sustained me through frustration and depression. Without his pushing me ahead, the completion of this thesis would be impossible.

I am also deeply indebted to the support of the Science Foundation of Jilin Agricultural University (Grant No. 20900040)

Special thanks should go to my friends and classmates who have in various ways put considerable time and effort into their comments on the draft.
Last but not the least, my gratitude also extends to my family who have been assisting, supporting and caring for me all of my life.

\section{REFERENCES}

[1] Robert J. Sternberg. Cognitive Psychology(Third Edition)[M] Beijing:Language Teaching and Research Press, 2003.

[2] Herbert J.Rubin. Qualitative Interviewing:The Art Of Hearing Data[M] Chongqing:Chongqing University Press, 2010.

[3] Peter W. Airasian. Classroom Assessment:Concepts \& Applications (Fourth Edition)[M] Shanghai:East China Normal University Press, 2008.

[4] Richards, Rodgers. Approaches and Methods in Language Teaching[M]. Cambridge:Cambridge University Press, 2000.

[5] Nunan, David. Second Language Teaching and Learning [M]. Beijing:Language Teaching and Research Press, 2001.

[6] Nunan, David. Designing Tasks for the Communicative Classroom [M]. Cambridge:Cambridge University Press, 1989.

[7] Ellis, R. Task-Based Learning and Teaching [M]. Oxford: Oxford University Press, 2003.

[8] Bygate, M. Researching Pedagogic Tasks: Second Language Learning, Teaching and Testing[M]. London: Longman, 2011.

[9] Johnson K. An Introduction to Foreign Language Learning and Teaching [M]. Beijing:Language Teaching and Research Press, 2003. 